\title{
Representações sociais de universitários sobre jovens e juventude
}

\author{
Social representations of students about younger crowds and the youth
}

\author{
Suzyelaine Tamarindo Marques da $\mathrm{Cruz}^{1}$ \\ Edinete Maria Rosa ${ }^{2}$ \\ Sabrine Mantuan dos Santos Coutinho ${ }^{3}$
}

\begin{abstract}
RESUMO: O estudo objetivou identificar as representações sociais de universitários de Vitória/ES sobre jovens e juventude. Participaram 308 jovens de ambos os sexos, na faixa etária de 18 e 29 anos, estudantes de universidades no município de Vitória, ES. Os dados foram coletados através de questionários de associação livre, 308 ao total, e 14 entrevistas individuais, sendo submetidos ao software EVOC e categorizados através da análise de conteúdo. Os resultados indicaram uma representação de jovem como alguém que está vivenciando uma fase de preparação para a vida adulta, de aquisição de responsabilidades com o futuro, mas também como alguém imaturo e rebelde, capaz de praticar atos ilícitos. A juventude foi, então, representada como uma fase de preparação para a vida adulta, através da faculdade, e ao mesmo tempo um período de curtição e liberdade.
\end{abstract}

Palavras-chave: juventude; jovens; universitários; representações sociais.

\begin{abstract}
The object of the study was to identify the students' social representations from Vitória/ES about younger crowds and the youth. 308 young adults of both sexes participated, between 18 and 29, college students in the city of Vitória, ES. The data were collected through questionnaires of free association, 308 in total, and 14 individual interviews, being submitted to the software EVOC and categorized through content analysis. The results showed a representation of a young person as someone who is going through a moment of preparation to the adult life, acquisition of responsibilities with the future, but also like an immature and rebel being, capable of illicit deeds. The youth was then represented as a moment of preparation to the adult life, through college, and at the same time a moment to be free and enjoy it.
\end{abstract}

Keywords: youth; young; university; social representations.

\section{Introdução}

A Organização Mundial da Saúde caracteriza os jovens como pessoas na faixa etária entre 15 e 24 anos de idade (WHO, 1986). Diferentemente, o Estatuto da Juventude (Brasil, 2013) considera que pessoas entre 15 e 29 anos estão vivendo a juventude. Por vezes atrelado ao conceito de adolescência, a juventude é também carregada de representações estereotipadas ao se referirem a tal segmento populacional como carregado por comportamentos naturalizados, condições e obrigações pré-determinadas (Valadão, 2013).

Há muito a temática da juventude consiste em um desafio acadêmico, pois apesar de debatido, ainda é marcado por uma diversidade de sentidos, por tratar-se de um fenômeno histórico e social. Perspectivas mais biológicas tendem a enxergar a juventude como um fenômeno natural delimitado por uma faixa etária específica, enquanto perspectivas mais

\footnotetext{
${ }^{1}$ Graduada em Psicologia pela Universidade Federal do Vale do São Francisco. Mestranda em Psicologia pela Universidade Federal do Espírito Santo - Vitória, ES, Brasil. E-mail: suzyelaine.marques@hotmail.com.

2 Pós-Doutora em Psicologia. Professora do Programa de Pós-graduação em Psicologia da Universidade Federal do Espírito Santo - Vitória, ES, Brasil.

3 Pós-Doutora em Psicologia. Professora do Curso de Psicologia da Universidade Federal Fluminense. Professora do Programa de Pós-graduação em Psicologia da Universidade Federal do Espírito Santo - Vitória, ES, Brasil.
} 
sociais, como é o caso da Psicologia Social, de modo geral, postulam que a juventude deve ser compreendida como um fenômeno histórico e social. Neste sentido, a presente investigação propõe-se a explorar o fenômeno da juventude junto a jovens universitários, e evidenciar as diferenças no que concerne aos gêneros, visando contribuir com a construção do conhecimento acerca de um fenômeno sempre atual e desafiador.

Para Menandro (2004), a construção social da juventude decorreu de uma série de mudanças no mundo do trabalho no século XIX a partir do que se pensava sobre a adolescência. Segundo a autora, a adolescência foi sendo construída a partir de demandas emergentes das transformações sociais ocasionadas pelas novas formas de trabalho capitalistas, demandando um tempo maior de preparo dos meninos para o exercício de certos ofícios, o que suscitou o aumento do período escolar e da dependência financeira dos pais (Menandro, 2004). A necessidade de uma preparação profissional prolongada, no período da industrialização, acabou por ocasionar o prolongamento da tutela familiar sobre os adolescentes, forçando a busca por perspectivas que delimitassem o fim da adolescência e demarcassem a juventude (Menandro, 2004; Peralva, 2007; Cassab, 2011).

A juventude caracteriza-se, de forma geral, como uma fase de preparação para a vida adulta (Goes-Piazzarollo, 2015). Groppo (2000; 2006), por exemplo, aborda a juventude como uma categoria social, uma fase que sucede a adolescência, sendo que esta está mais próxima da infância e essa mais próxima à idade adulta ou à maturidade. Tal categoria, de acordo com Santos, Almeida, Mota e Medeiros (2010), começou a receber atenção dos pesquisadores a partir do século XX; entretanto, havia tendência a considerar os jovens como problemáticos ou como difíceis de lidar (Abramo, 1997).

Na Psicologia, Stanley Hall foi um dos teóricos que contribuiu para a construção do conceito de juventude. $\mathrm{O}$ autor caracterizou o período da adolescência e da juventude como uma fase universal caracterizada pela turbulência e instabilidade emocional (Menandro, Trindade \& Almeida, 2010; Pais, 1990; Pappámikail, 2010). Tal concepção foi hegemônica na Psicologia durante muito tempo e permanecem no imaginário social até hoje (Ozella, 2003).

Estudos de cunho sociológico tentam entender a juventude e a adolescência em função das suas experiências de vida, que se relacionam à sua condição socioeconômica, cultural, étnica e escolar (Menandro, 2004; Cardoso \& Sampaio, 1995). Dentre esses, podemos citar os estudos da antropologia social e da psicologia sócio-histórica, que trouxeram novas contribuições para o entendimento da juventude como uma categoria marcada não somente por fatores biológicos e psicológicos, mas, sobretudo, por fatores sociais e culturais, como apontam Aguiar, Bock e Ozella (2001).

Partindo desta perspectiva, Bock, Furtado e Teixeira (2008) ponderam que a juventude pode ser considerada fruto da estrutura socioeconômica e cultural. Assim, é importante pensá-la para além da cronologia e considerar os demais fatores que influenciam e ajudam a construir socialmente e historicamente a juventude.

Pappámikail (2010) trata a juventude como uma "condição duplamente etária e cultural" (p. 398), marcando as variantes sociais que interferem na forma como a concebemos. Segundo ela, a condição juvenil é um processo de mudança que, na sociedade moderna ocidental, é legitimado como período para socialização, interação e aprendizagem, rumo a uma preparação para a vida adulta. Segundo a autora, para pensar a juventude como uma categoria sociocultural, é válido considerar os aspectos simbólicos, culturais e fisiológicos do desenvolvimento, já que hoje "cresce-se mais cedo, mas emancipa-se cada vez mais tarde" (p. 398). Esse prolongamento da juventude, observado quando 
consideramos jovens de classe média e alta, ocorre, sobretudo, por transformações culturais, pela universalização do acesso à escola e a extensão das carreiras escolares, à velocidade e instantaneidade dos meios de comunicação, transformações no mercado de trabalho e consequente adiamento da saída da casa dos pais, da procriação e do casamento (Pais, 2009; Pappámikail, 2010).

Alguns estudos anteriores já abordaram a temática da representação social sobre jovem e juventude. Vale ressaltar que em muitos estudos "adolescência" e "juventude" são considerados sinônimos. O estudo de Menandro, Trindade e Almeida (2010) sobre representações sociais da adolescência/juventude a partir de textos jornalísticos. As autoras encontraram uma representação dos jovens como estudantes secundaristas ou universitários; a juventude foi representada por um período para se divertir e aproveitar a vida e como um período de transição.

Paixão, Almeida e Lima (2012) ao investigarem representações sociais da adolescência por adolescentes e jovens, encontraram como resultados a ligação entre jovens e transgressão; os jovens compreenderam os adolescentes como pessoas que vivenciam uma fase marcada pela curtição; encontraram ainda a rebeldia como uma das marcas da juventude.

O trabalho intergeracional apresentado por Pappámikail (2004) sobre representações de pais e filhos, sobre o apoio familiar às transições para a vida adulta, abordou o modo como vem se configurando a juventude europeia, caracterizada pela extensão das trajetórias escolares e pelo progressivo adiamento dos processos de emancipação dos jovens da família. Os resultados apontaram as famílias como apoiadoras dos filhos, que foram encarados em alguns casos como projetos de realização dos pais. O modelo de desenvolvimento individual ideal que perpassava as falas de pais e filhos coloca a qualificação e a realização profissional como centro, o que acarreta no adiantamento do processo de emancipação dos jovens (Pappámikail, 2004).

É a noção de juventude construída socialmente em meio a um cenário econômico, cultural e histórico que estamos adotando neste trabalho, não como uma etapa transitória e universal. Compreendendo este processo de maturação não apenas como sendo o que não é adolescência e o que não é adultez, e sim como um momento da vida que está ligado a outros momentos, o que não significa que é um momento exclusivo de preparação para a vida adulta (Ozella, 2003b; Menandro, Trindade \& Almeida, 2010). Como bem disse Soares (2000), ao desconsiderar a juventude como simplesmente uma fase da vida

O que se quer afirmar é que a concepção de juventude como um tempo de transição deve ser re-elaborada a partir da consideração de que toda a vida do ser humano se desenvolve entre transições e que, apesar disso, cada etapa, cada momento, 'cada transição' tem seu sentido próprio e, sobretudo, suas expectativas próprias (p. 83). Assim, considera-se que pensar a juventude como um tempo de transição, equivale a encará-la como um momento autônomo, com sentidos próprios, não somente como uma fase de preparação para a fase seguinte.

Compartilhamos neste estudo das ideias de Carrano (2011), que afirma a necessidade de encarar a juventude como tendo um valor próprio, não somente como uma etapa de transição, mas como um momento do ciclo da vida no qual a pessoa é agente do seu destino e capaz de realizar as suas próprias escolhas biográficas. Pensando na experiência juvenil como sendo dotada de valor de experiência e sentido pessoal que está para além do período de preparação para a fase adulta, instigou-nos conhecer as representações forjadas sobre o 
jovem e a juventude, por universitários, uma vez que à Universidade foi atribuída, historicamente, a função de preparar o jovem para ingressar no mercado de trabalho e, consequentemente, na vida adulta. Assim, tentar apreender como universitários - jovens que socialmente são representados como aqueles que correspondem às expectativas sociais positivas e tradicionais a respeito da juventude, além de expor como os mesmos compreendem a si e ao grupo do qual fazem parte, pode contribuir teoricamente na compreensão de como a elaboração das representações de si podem ser influenciadas pelos discursos elaborados socialmente.

Para atingir o objetivo da pesquisa, - compreender as representações sociais de jovens universitários sobre jovens e juventude - apoiamo-nos parcialmente na abordagem estrutural das representações sociais, proposta por Abric (1998), para quem uma representação está organizada em torno de um núcleo central, que organiza e dá sentido à representação, e um sistema periférico, que atualiza e protege os elementos centrais, ao mesmo tempo em que abriga possíveis diferenças individuais e grupais de uma RS (Paixão, Almeida \& Lima, 2012); e parcialmente na abordagem processual proposta por Moscovici e aprimorada pelos estudos de Jodelet, que defende que as representações não devem ser conhecidas somente enquanto sistemas de interpretação da realidade e guia de condutas, uma vez que elas interferem na forma como difundimos e assimilamos o conhecimento, desenvolvemo-nos enquanto seres individuais e coletivos, definimos nossa identidade pessoal e social, e no modo como a realidade social se transforma (Chaves \& Silva, 2011).

Para Abric (1998), as representações sociais têm várias funções: como forma de saber, a partir dos conhecimentos já existentes, pode-se construir outros novos, atrelandoos aos primeiros; como função identitária, permite ao indivíduo se situar em determinado grupo social, possibilitando a construção de uma identidade pessoal e social; como função de orientação, prescreve comportamentos e práticas que são aceitáveis, esperadas e obrigatórias em determinado contexto social, ou seja, são como guias; e na função justificadora após a ocorrência de uma determinada ação para justificá-la face ao outro grupo.

Arruda (2005), referindo-se as maneiras relacionadas à interpretação dos resultados usando tal teoria, afirma que esta lida com "as maneiras como os grupos dão sentido ao real, elaborando-o e explicando para si mesmos, para se comunicarem e funcionarem cotidianamente" (p.231). Diante disso, a fim de compreender as representações sociais de certo grupo, é importante conhecer o princípio interno dessa representação e a relação estabelecida com o mundo.

\section{Método}

\section{Caracterização dos participantes}

Participaram do estudo 308 jovens, na faixa etária de 18 e 29 anos ( $M=20,47$; $\mathrm{DP}=2,51$ ), sendo 184 do sexo masculino e 124 do sexo feminino, estudantes universitários de instituições públicas e privadas de Vitória/ES, dos cursos de: direito, arquitetura, psicologia, física, engenharia mecânica, jornalismo, matemática e história. A escolha dos participantes deu-se pelo critério de conveniência; assim, para localizar os jovens que cumpriam os requisitos de participação na pesquisa, fomos até às universidades, locais de ampla circulação de jovens, garantindo a diversidade da amostra. Os participantes foram convidados a participarem da pesquisa nas salas de aula, em horários cedidos pelos 
professores, após a apresentação dos objetivos da pesquisa. Aos que se dispuseram a participar, foi entregue o Termo de Consentimento Livre e Esclarecido (TCLE) e o questionário. Após terem respondido o primeiro instrumento, os participantes foram convidados a participarem das entrevistas individuais. Dentre estes participantes, conseguimos entrevistar 14 deles, pois apesar de terem deixado o contato, quando tentamos marcar houve incompatibilidade de horários, alguns desistiram e outros marcaram e não compareceram à entrevista.

\section{Instrumentos}

Dois instrumentos foram utilizados: $O$ primeiro foi um questionário com questões de associação livre de palavras, com os termos indutores jovens e juventude, e sociodemográficas; $O$ segundo instrumento utilizado foi um roteiro de entrevista com questões abertas abordando a temática da juventude, como por exemplo: "Você acha que há alguma diferença entre juventude, jovens e adolescentes? Se sim, qual? Para você, o que é a juventude? Como é ser jovem nos dias atuais?".

O primeiro instrumento foi aplicado de forma coletiva, nas salas de aula, o tempo de duração foi em média 40 minutos. As entrevistas foram aplicadas individualmente em uma sala do prédio do Programa de Pós-graduação em Psicologia e duraram em média 70 minutos. A utilização dos dois instrumentos nos ajudou a apreender as opiniões e representações dos jovens pesquisados acerca da juventude, tornando possível uma caracterização da estrutura e do conteúdo da representação social de jovem e juventude para os mesmos.

\section{Procedimento de análise dos dados}

Buscando identificar as representações sociais de jovem e juventude entre os jovens pesquisados, foram realizadas duas etapas de análise: na primeira delas submeteu-se os dados de evocação livre à análise prototípica desenvolvida por Vergés (1992). Tal técnica está ligada à teoria do núcleo central e analisa as evocações com base na saliência dos elementos, cruzando a frequência e a ordem de evocação (Polli \& Wachelke, 2013). A análise prototípica foi realizada através do software EVOC (Ensemble de programmes permettant l'analyse des évocations), que identifica, a partir de uma lista ordenada de evocações livres, os elementos centrais e periféricos das representações sociais a partir do cruzamento de três indicadores: palavras mais frequentes, palavras mais prontamente evocadas e palavras indicadas pelos sujeitos como sendo as mais importantes para designar o objeto da representação (Almeida, 2005).

O EVOC organiza os termos em quatro quadrantes de acordo com a frequência e a ordem. No primeiro, são apresentados os elementos que aparecem com maior frequência e nas primeiras posições, o que pode indicar os elementos constituintes do núcleo central. No segundo quadrante, são expressos os termos que apresentaram alta frequência, porém mencionados nas últimas posições; no terceiro quadrante, aparecem aqueles que apresentaram baixa frequência, mas foram nas primeiras posições. Os termos organizados no quarto quadrante são aqueles que se localizam na periferia distante, apresentam baixa frequência e que são mencionados nas últimas posições.

$\mathrm{Na}$ segunda etapa da análise de dados buscou-se analisar os dados das entrevistas individuais. Para a organização e categorização dos dados obtidos com as entrevistas, 
utilizou-se a Análise de Conteúdo Temática da forma proposta por Bardin (2011). Inicialmente foi feita uma leitura exaustiva do material textual obtido e, de acordo com os objetivos pretendidos no estudo, classificamos as respostas dos participantes em categorias sob um título genérico em virtude das características comuns, o critério de categorização foi o semântico, assim, todos os temas que significavam a juventude, por exemplo, ficaram na categoria definições de juventude. Em cada categoria foram enquadrados elementos com aspectos comuns.

As respostas dos participantes foram agrupadas nas seguintes categorias: 1) Conceito de jovens; 2) Diferenciação entre jovens e adolescentes; 3) Definições de juventude; 4) A vivência da juventude na sociedade atual. Dentro de tais categorias existiam subcategorias, por exemplo, dentro da categoria 3, as respostas foram agrupadas nas subcategorias 3.1. Momento de diversão; 3.2. Momento de decisões e descobertas; 3.3. Momento de liberdade; 3.4. Construção Social.

\section{Resultados e discussão}

Iniciaremos apresentando os resultados obtidos na análise do instrumento I. A apresentação dos resultados se baseará nas diferenças e semelhanças das respostas dos participantes a partir da variável 'sexo'.

Para introduzir o debate sobre a juventude, iniciamos perguntando aos jovens quais as cinco palavras ou expressões que Ihes vinham à cabeça quando ouviam o termo indutor "jovens". A análise prototípica utilizada permitiu uma primeira caracterização da estrutura e do conteúdo da representação. A Tabela 1 retrata a distribuição das evocações dos jovens do sexo masculino, conforme os critérios de frequência e ordem média de evocação referente ao termo "jovens". De um total de 615 termos evocados, 192 termos diferentes. A ordem média de importância foi 2,8 . A frequência intermediária foi de 12 , correspondente a 227 evocações ou 36,9\% do total de 615. A distribuição das evocações dos jovens do sexo masculino, conforme os critérios de frequência e ordem média de importância referente ao termo jovens é apresentada na Tabela 1:

Tabela 1 - Análise prototípica referente às evocações de jovens do sexo masculino acerca do tema indutor Jovens

\begin{tabular}{|c|c|c|c|c|c|}
\hline \multicolumn{4}{|c|}{ Ordem média de evocação $<2,8$} & \multicolumn{2}{|c|}{ Ordem média de evocação >= 2,8 } \\
\hline \multicolumn{6}{|c|}{ Frequência >= 12} \\
\hline Estudo & 28 & 2,107 & Balada & 45 & 3,289 \\
\hline Faculdade & 15 & 2,267 & Disposição & 14 & 3,000 \\
\hline Futuro & 21 & 2,762 & Diversão & 17 & 3,176 \\
\hline \multirow[t]{3}{*}{ Sexo } & 23 & 2,478 & Drogas & 31 & 3,806 \\
\hline & & & Rebeldes & 15 & 3,267 \\
\hline & & & Álcool & 18 & 4,056 \\
\hline \multicolumn{4}{|c|}{ Ordem média de evocação $<2,8$} & \multicolumn{2}{|c|}{ Ordem média de evocação >= 2,8 } \\
\hline \multicolumn{6}{|c|}{ Frequência $<12$} \\
\hline Adolescente & 8 & 1,875 & Amigos & 7 & 3,571 \\
\hline Alegria & 8 & 2,000 & Curtição & 6 & 2,833 \\
\hline Amizade & 10 & 2,300 & Esporte & 7 & 4,143 \\
\hline Emprego & 6 & 2,333 & Imaturidade & 10 & 3,100 \\
\hline Escola & 7 & 2,000 & Indecisos & 6 & 2,833 \\
\hline Inconsequentes & 9 & 2,778 & Liberdade & 8 & 2,875 \\
\hline Mudança & 8 & 2,750 & Namoro & 8 & 3,625 \\
\hline Vitalidade & 6 & 2,500 & Violência & 6 & 3,833 \\
\hline
\end{tabular}


O quadrante superior esquerdo da Tabela 1 permite uma visualização dos possíveis elementos centrais da representação de jovens para os participantes, uma vez que aí aparecem os termos mais prontamente evocados pelo maior número de sujeitos: estudo, faculdade, futuro e sexo. Se considerarmos somente a distribuição de frequências, estudo, sexo e futuro poderiam ser considerados os mais centrais pela diferença em relação à palavra faculdade, cuja frequência está mais próxima da frequência intermediária. 0 segundo quadrante, de altas frequências e altas ordens de evocação, balada, disposição, diversão, drogas, rebeldes e álcool.

No segundo quadrante, encontramos os termos balada, disposição, diversão, drogas $e$ rebeldes. O elemento drogas, apesar de não compor o núcleo central, é um elemento importante na configuração da RS de jovens, pois é o elemento mais frequente e com altíssima média de evocação. O uso abusivo de drogas é considerado um problema de ordem social e, segundo Espíndula, Alves, Carvalho, Almeida e Cruz (2015), a juventude é considerada como o grupo mais vulnerável ao envolvimento com as drogas.

$\mathrm{Na}$ tabela 2, são apresentados os resultados da análise prototípica referente às evocações de jovens do sexo feminino para o tema indutor Jovens. O total de evocações foi 918 e a ordem média de evocação foi 2,8. A frequência intermediária foi de 16, correspondente a 324 evocações ou $35,2 \%$ do total de evocações.

Tabela 2 - Análise prototípica referente às evocações de jovens do sexo feminino acerca do tema indutor Jovens

\begin{tabular}{|c|c|c|c|c|c|}
\hline \multicolumn{3}{|c|}{ Ordem média de evocação < 2,8 } & \multicolumn{3}{|c|}{ Ordem média de evocação >= 2,8 } \\
\hline \multicolumn{6}{|c|}{ Frequência >= 16} \\
\hline Amizade & 35 & 2,571 & Alegria & 27 & 3,111 \\
\hline Estudo & 43 & 2,744 & Balada & 52 & 3,404 \\
\hline Faculdade & 16 & 2,500 & Diversão & 38 & 3,184 \\
\hline Futuro & 23 & 2,348 & Drogas & 28 & 3,536 \\
\hline \multirow[t]{2}{*}{ Liberdade } & 27 & 2,593 & Irresponsáveis & 17 & 3,647 \\
\hline & & & Rebeldes & 18 & 2,833 \\
\hline \multicolumn{3}{|c|}{ Ordem média de evocação < 2,8 } & \multicolumn{3}{|c|}{ Ordem média de evocação >= 2,8 } \\
\hline \multicolumn{6}{|c|}{ Frequência $<16$} \\
\hline Decisões & 11 & 2,545 & Amadurecimento & 10 & 3,100 \\
\hline Energia & 10 & 2,400 & Bebida & 15 & 3,667 \\
\hline Estudantes & 8 & 2,000 & Curtição & 11 & 3,182 \\
\hline Família & 9 & 1,889 & Emprego & 15 & 3,600 \\
\hline Força & 8 & 2,250 & Escola & 10 & 3,000 \\
\hline Redes sociais & 8 & 2,750 & Imaturidade & 12 & 3,000 \\
\hline Sexo & 15 & 2,733 & Inconsequentes & 13 & 3,692 \\
\hline Vida & 14 & 2,500 & Namoro & 12 & 3,333 \\
\hline \multirow[t]{4}{*}{ Vitalidade } & 10 & 2,000 & Novidade & 10 & 2,900 \\
\hline & & & Responsabilidades & 12 & 3,083 \\
\hline & & & Tecnologia & 12 & 3,000 \\
\hline & & & Violência & 12 & 3,500 \\
\hline
\end{tabular}

As palavras que possivelmente constam no centro da representação são amizade, estudo, faculdade, futuro e liberdade, segundo a análise feita pelo EVOC. No segundo quadrante, de altas frequências e altas ordens de evocação, aparecem alegria, balada, diversão, drogas, irresponsáveis e rebeldes. A distribuição de frequências pode sugerir que balada, diversão, amizade, futuro, estudo e drogas sejam centrais, pela diferença em relação 
às palavras faculdade, irresponsáveis e rebeldes, cujas frequências estão mais próximas da frequência intermediária.

Na periferia, os termos sexo, bebida, namoro, tecnologia e redes sociais parecem falar sobre práticas comuns na juventude, ou seja, atividades que os jovens se importam e destinam boa parte do tempo. Energia, estudantes, força, vitalidade e vida seriam características positivas dos jovens e são, geralmente, enaltecidas e até lembradas com saudosismo pelos adultos, por exemplo. Violência, inconsequentes $e$ imaturidade são os termos que denotam características negativas aos jovens.

Comparando os dados das duas tabelas (jovens do sexo masculino e jovens do sexo feminino), em relação ao termo indutor jovens, estudo, futuro e faculdade são elementos comuns ao primeiro quadrante das duas tabelas, o que, de certa forma, está ancorado nos discursos do jovem como um ser que precisa se dedicar à formação profissional para o ingresso no mundo adulto, como salientaram Menandro (2004), Peralva (2007) e Cassab (2011). Podemos perceber que, paralela a esta visão de jovem focada na preparação para o futuro, elementos como diversão, balada, drogas, liberdade e amizade enfocam um outro lado da juventude vivenciada, a liberdade que o jovem usufrui por não possuir as responsabilidades do mundo adulto, o que Menandro, Trindade e Almeida (2010) chamou de "compromisso com o prazer".

Percebe-se, então, que o imperativo capitalista de produção e consumo está cada vez mais direcionando os jovens a investir na formação profissional, de modo que se na vida adulta o trabalho se torna central, na juventude o estudo torna-se central, ao passo que o tempo destinado ao lazer e ao ócio, tão valorizado pelos jovens, se reduz a cada dia, o que implica na diminuição da liberdade de escolha em relação a como gerir a sua própria vida, pois precisam abdicar dos momentos de prazer para dedicar-se às atividades de caráter obrigatório, como também observaram Oliveira (2015) e Martins, Lefevre, Lefevre e Oliveira (2012).

As categorias que parecem estruturar o núcleo central da RS de jovens para os jovens investigados são o estudo (universidade ou escola, já que os mesmos não citaram os cursos técnicos como preparatórios para o mercado de trabalho), como fator central para a preparação para o ingresso no mercado de trabalho, como valor fundamental da juventude, associado à condição social de jovem responsável, ou do que se espera do jovem; e a diversão, que pode estar ligada ao aproveitamento do tempo livre e à visão do jovem como rebelde e transgressor de normas e regras, remetendo às representações de jovens que estão escritas na sociedade ocidental e que associam o jovem à transgressão de normas e leis estabelecidas socialmente (Paixão, Almeida \& Lima, 2012).

Imaturidade, inconsequentes e violência, elementos periféricos das duas representações, também apontam contradições à visão do jovem estudante, remontando à ideia de juventude como uma fase turbulenta e instável e, por isso, o jovem como mais suscetível a envolver-se com problemas sociais ou até mesmo a tornar-se um problema social, como apontaram Oliveira e Rosa (2010). A imagem do jovem objetivada na imagem do estudante, ou do aprendiz de adulto, condiz com a imagem que circula na mídia de um jovem de classe média/alta, que deve dedicar-se ao estudo e ao lazer, corroborando com os achados de Menandro (2004). Estas ideias sobre o jovem podem ser reforçadas quando nos atentamos às realidades vividas por estes jovens, em sua maioria de classe média, todos universitários em busca de uma formação profissional, porém sem abrir mão dos prazeres que podem usufruir. 
É interessante notar que ao falarem dos jovens, os participantes estão falando de si e do seu grupo, por isso a impressão de que ao se referirem ao que é esperado socialmente dos jovens, eles falam sobre o que é esperado deles próprios, jovens de classe média, que foram tomados como o parâmetro para se definir o que é e o que deve fazer um jovem. Espera-se que eles se preparem para ingressar no mundo adulto por meio do mercado de trabalho, que está cada dia mais exigente e competitivo. As falas das entrevistas ilustram o que acabamos de afirmar:

\begin{abstract}
Não, tipo assim, o que pesa muito quando pensamos na questão dos jovens ou não é o quanto você já está encaminhando a sua vida e o quanto você já está pensando em fazer as suas próprias coisas, entende? 0 quanto você já se preocupa com isso. Eu não trabalho, como eu estudo aqui na UFES o dia inteiro e eu sou sustentado pelos meus pais, então tipo, eles me dão uma mesada e com essa mesada eu me viro, eles não me dão nem mais nem menos dinheiro, só aquilo que eu vou sobreviver assim no mês... tipo, eu moro com eles, mas tem um monte de gente que faz a mesma coisa e só não mora com os pais, tipo... eu conheço um monte de gente que vem de lugares mais longes e tem casa aqui, mas são sustentados $100 \%$ pelos pais, mas já é mais independente, já tem que cuidar do próprio dinheiro para gastar com as coisas, entende?. [...] Eu acho que a juventude seria aquele momento da vida que você já tem uma vida adulta, já pode sair, fazer suas próprias coisas, já pode dirigir, beber, fazer coisas assim que você não podia quando você era adolescente, mas você realmente não tem aquela preocupação de "ah, eu tenho que dar uma vida boa para a minha família, eu tenho que cuidar dos meus filhos, tenho que procurar contas de escola, de creche", sabe? Ao mesmo tempo em que temos mais responsabilidades, não temos tanto quanto os adultos. Você tem uma liberdade maior e tem uma consequência de liberdades menores, você pode fazer mais coisas sem se preocupar tanto com as consequências do dinheiro que você está gastando, porque elas não são $100 \%$ suas, seus pais estão ali para te ajudar ainda (M 6).
\end{abstract}

A fala acima ilustra bem a dicotomia representada e vivenciada pelos próprios jovens que, ao mesmo tempo em que assumem responsabilidades de pensar no seu futuro, tem liberdade de aproveitar ao máximo os amigos, as festas, ou seja, tem um compromisso com o prazer, uma vez que eles ainda não são socialmente responsabilizados por todos os seus atos. As categorias estruturantes do núcleo central da representação de jovens parecem girar, portanto, em torno das noções de responsabilidade (atrelada ao compromisso com a preparação para a adultez) e rebeldia (ligada à diversão e a prática de atos que infringem normas e regras).

Como bem salientou Andrade (2000), a representação que um sujeito faz de determinado objeto é um bom indício do perfil de sua identidade, bem como o conhecimento da identidade de alguém é um bom preditor de sua visão de mundo, já que a identidade é construída individual e coletivamente. O que percebemos na RS de jovem é que a mesma é constituída por uma dinâmica social - normas e valores que ditam como um jovem deve ser e o que é esperado socialmente dele - e uma dinâmica individual ou identitária, que diz respeito ao modo como cada jovem se apropria do mundo social e dos conhecimentos que nele circulam e elaboram psicologicamente e socialmente essa realidade social e age de acordo com ela. Um dos jovens entrevistados apontou bem como vivencia a sua juventude ao ser questionado sobre o que é ser jovem na sociedade atual:

Então, eu estudo, muitos jovens trabalham, mas eu ainda estou procurando um trabalho, se não eu estaria trabalhando. Eu tento aproveitar o máximo possível, faço dela um momento de diversão, tento não ficar só nos estudos, tento me dividir e mesclar um pouco para não ficar monótono e depois dizer que eu estudei a minha juventude inteira ou trabalhei a vida inteira $e$ deixei de aproveitar, então eu tento fazer... juntar tudo, o estudo, o trabalho e a diversão. (M5).

Nas entrevistas, os jovens foram caracterizados e definidos a partir de três características principais: a faixa etária, os jovens foram apontados como pessoas que estão 
na faixa etária superior à da adolescência e inferior à da adultez, mostrando que as delimitações etárias presentes no estatuto da Juventude ou em alguns estudos sobre os jovens estão presentes nas representações de juventude; a maturidade ou as experiências vividas, sendo os jovens julgados como mais maduros e mais semelhantes aos adultos quando comparados aos adolescentes, porém com menos responsabilidades; e as diferenças no processo de desenvolvimento, pois enquanto os adolescentes estariam passando por um momento de mudanças corporais e por um momento de construção da personalidade, o jovem estaria em um processo de "descobrimento" do seu lugar perante a sociedade e o "mundo adulto", o que ratifica a compreensão do jovem como alguém que está se preparando para a adultez.

Sendo assim, a partir das falas é possível observar que os jovens tentam formar uma identidade de si e do seu grupo a partir da diferenciação entre este e outros grupos, no caso o grupo de adolescentes e o grupo de adultos. De acordo com o que foi discutido sobre a construção social da juventude, parece que os jovens, ao elencar elementos impares à juventude tentam demarcar o que a define e diferencia, e tendo em vista as visões estereotipadas que giram em torno da adolescência, não é de se estranhar que os jovens tentem afastar-se deste grupo, colocando os jovens como imaturos e irresponsáveis, e busquem uma aproximação com o grupo dos adultos, grupo considerado ideal, ao ressaltarem a maturidade e a responsabilidade. As falas a seguir exemplificam o que foi dito:

O adolescente, quando eu penso nele eu penso mais em imaturidade, entendeu? Quando eu penso em jovem, eu penso assim um pouco mais abrangente, não que não abranja o adolescente, mas quando me vêm juventude à cabeça, me vem assim festas, baladas, mas ao mesmo tempo me vem faculdade. Já quando eu penso no adolescente não, me vem aquela população que está passando por aquele monte de mudanças corporais e que estão em muitos conflitos com eles mesmos e eu acho que é isso assim, eu não consigo ver os dois como a mesma coisa. (F1)

Acho que é a questão da maturidade mesmo. Quando a gente tem, por exemplo, hoje eu já me considero mais jovem assim, porque eu já faço coisas de adulto, sou mais adulta apesar de ser jovem, mas não tenho todas as responsabilidades de um adulto, que os pais têm. Agora adolescente não, adolescente é aquela pessoa que tem lá seus 15 ou 14 anos, sabe? 16, e está vivendo uma outra... ele pode até achar que não, mas é totalmente dependente dos pais, ele não tem independência nenhuma, nada, se quer ir à casa de um amigo pede para o pai levar, coisas $\operatorname{assim}(\mathrm{M6})$.

As representações dos jovens - apesar de todas as significativas diferenças que podem ser proporcionadas pelo gênero, pela área profissional e pelo status socioeconômico, predisposições intelectuais, em decorrência da maneira de enxergar e pensar os diversos objetos sociais e de gênero - não parecem diferir muito como observamos ao analisar os sentidos e os significados das evocações. A semelhança notável, mas não absoluta, entre os núcleos centrais indica que, embora não sejam as mesmas representações mantidas identicamente por jovens do sexo feminino e do sexo masculino, elas são simbolicamente semelhantes.

Os elementos comuns básicos que parecem formar o núcleo central da representação de jovens para os participantes do sexo masculino (estudo, faculdade, futuro e sexo) representam quase a totalidade dos elementos citados pelas jovens do sexo feminino, a diferença é que sexo não aparece no NC da representação delas, apesar de aparecer na periferia com um índice quase igual à frequência média (15, F=16), mas é ampliado com os termos amizade e liberdade, que por sinal também estão presentes na periferia da RS dos jovens. Os elementos parecem caracterizar o momento de vida atual dos participantes e ao 
mesmo tempo, tratam de elementos representacionais de identificação com as crenças e normas sociais criadas sobre o jovem, as quais variam em função das categorias de gênero e das classes sociais e são demarcadas cotidianamente na vida cotidiana dos jovens através dos discursos da família e da mídia, por exemplo.

Agora vamos nos ater às discussões sobre a juventude, iniciando com o que foi evocado pelos jovens do sexo masculino. Somente 107 jovens do sexo masculino responderam à questão cujo termo indutor foi Juventude, somando 17 casos omissos, o que não reduz a validade dos dados obtidos. De um total de 529 evocações, 191 termos diferentes foram citados. A ordem média de evocações foi de 2,8; a frequência intermediária foi 10 , correspondente a 123 evocações nos núcleos mais centrais, o equivalente a $23,25 \%$ do total de evocações. O ponto de corte foi 3. Abaixo, na tabela 3, podemos visualizar os resultados da análise feita pelo EVOC:

Tabela 3 - Análise prototípica referente às evocações de jovens do sexo masculino acerca do tema indutor Juventude

\begin{tabular}{|c|c|c|c|c|c|}
\hline \multicolumn{3}{|c|}{ Ordem média de evocação < 2,8 } & \multicolumn{3}{|c|}{ Ordem média de evocação >= 2,8 } \\
\hline \multicolumn{6}{|c|}{ Frequência $<10$} \\
\hline Estudo & 14 & 2,429 & Alegria & 12 & 2,917 \\
\hline Fase & 14 & 2,214 & Amigos & 10 & 2,900 \\
\hline \multirow{4}{*}{ Religiosidade } & \multirow{4}{*}{10} & \multirow{4}{*}{1,900} & Balada & 20 & 3,550 \\
\hline & & & Bebida & 11 & 4,000 \\
\hline & & & Drogas & 17 & 3,941 \\
\hline & & & Sexo & 13 & 2,846 \\
\hline \multicolumn{3}{|c|}{ Ordem média de evocação $<2,8$} & \multicolumn{2}{|c|}{ Ordem média de evocação >= 2,8 } & \\
\hline \multicolumn{6}{|c|}{ Frequência $<10$} \\
\hline Aprendizado & 6 & 2,667 & Curtição & 8 & 2,875 \\
\hline Descobertas & 6 & 2,167 & Decisões & 7 & 3,143 \\
\hline Desenvolvimento & 6 & 2,667 & Escola & 6 & 3,667 \\
\hline Futuro & 9 & 2,333 & Esperança & 6 & 2,833 \\
\hline Irresponsabilidade & 7 & 2,714 & Grupos & 7 & 3,571 \\
\hline Responsabilidade & 9 & 1,889 & Jovem & 6 & 3,000 \\
\hline Saúde & 6 & 1,833 & Música & 6 & 3,500 \\
\hline Vida & 6 & 2,000 & Rebeldia & 7 & 2,857 \\
\hline \multirow[t]{3}{*}{ Vitalidade } & 8 & 2,250 & Redes Sociais & 6 & 3,500 \\
\hline & & & Trabalho & 6 & 2,833 \\
\hline & & & Violência & 6 & 4,833 \\
\hline
\end{tabular}

Estudo, fase e religiosidade são as palavras que compõe o núcleo central, tendo sido evocadas por um número significativo de jovens e mais prontamente. Ao observar somente a saliência, frequência das palavras, percebe-se que o núcleo central poderia ser composto pelos termos: balada, drogas, fase e estudo. Estima-se que balada e drogas sejam as palavras mais centrais, tendo em vista a frequência elevada que as separam das demais palavras.

O termo religiosidade foi ressaltado em alusão aos movimentos juvenis de cunho religioso. Fazendo um paralelo com o estudo de Martins, Trindade e Almeida (2003), a religiosidade foi tratada pelos adolescentes e jovens como importante para lidar com a vida e superar as adversidades. As autoras ressaltaram a necessidade de alguns participantes de sustentar a vida em torno da fé, pois por meio dela se consegue força para seguir no caminho certo e ser amado (Martins, Trindade \& Almeida, 2003). 
Nos dois quadrantes inferiores da figura encontramos termos que se referem mais prontamente a características da juventude, como vida e vitalidade, que puderam ser agrupadas pela semelhança, saúde e jovem; desenvolvimento, aprendizado, descobertas e decisões que são termos normalmente utilizados para se referir à juventude como uma fase da vida preparatória para a vida adulta, na qual as responsabilidades são mais flexíveis e o aprendizado e as decisões sobre o futuro imperam.

Se por um lado é esperado que o jovem estude e trabalhe para adquirir responsabilidades, por outro a violência e a irresponsabilidade aparecem para marcar e reafirmar características negativas atribuídas ao grupo e reproduzidas nas falas dos próprios jovens, afinal, como salientaram Cassab (2011), Valadão (2013) e Vavassori e Toneli (2015), os discursos que associam juventude, sobretudo das periferias urbanas, a contextos de violência e criminalidade, demarcando os jovens como problemas ou possíveis problemas sociais são recorrentes e difundidos em nossa sociedade há muito tempo, servindo assim de ancoragem para as representações dos próprios jovens acerca da população juvenil.

A tabela 4 que apresenta os resultados provenientes da análise prototípica referente às evocações de jovens do sexo feminino acerca do tema indutor Juventude. Dos 180 respondentes, obtivemos 887 evocações e 250 palavras diferentes. A ordem média de evocações foi 2,9 , e a frequência intermediaria igual a 17 , correspondente a $27,2 \%$ das evocações. A frequência mínima foi 8.

Tabela 4 - Análise prototípica referente às evocações de jovens do sexo feminino acerca do tema indutor Juventude

\begin{tabular}{|c|c|c|c|c|c|}
\hline \multicolumn{3}{|c|}{ Ordem média de evocação < 2,9 } & \multicolumn{3}{|c|}{ Ordem média de evocação >= 2,9 } \\
\hline \multicolumn{6}{|c|}{ Frequência $<10$} \\
\hline Educação & 22 & 2,864 & Amigos & 35 & 2,971 \\
\hline Fase & 28 & 2,500 & Balada & 21 & 3,143 \\
\hline Liberdade & 26 & 2,154 & Descobertas & 18 & 2,944 \\
\hline \multicolumn{3}{|c|}{ Ordem média de evocação < 2,9 } & \multicolumn{3}{|c|}{ Ordem média de evocação >= 2,9 } \\
\hline \multicolumn{6}{|c|}{ Frequência $<10$} \\
\hline Desenvolvimento & 9 & 2,556 & Drogas & 8 & 4,125 \\
\hline Esperança & 9 & 2,667 & Emprego & 14 & 3,214 \\
\hline Experiências & 10 & 2,300 & Escolhas & 12 & 3,000 \\
\hline Mudanças & 16 & 1,938 & Passageira & 8 & 3,750 \\
\hline Oportunidades & 8 & 2,750 & Sexo & 8 & 3,375 \\
\hline Tecnologia & 10 & 2,700 & Violência & 8 & 3,250 \\
\hline
\end{tabular}

No primeiro quadrante encontram-se: aprendizado, liberdade, responsabilidade, fase $e$ educação. Pode-se indicar pelo estudo da saliência dos elementos que amigos, alegria, diversão, fase e liberdade parecem ser os elementos prováveis do núcleo central.

Com os elementos da periferia, podemos fazer a seguinte associação: juventude é um período da vida marcado por mudanças, oportunidades, desenvolvimento, escolhas, novidade e é uma fase passageira, mas cheia de experiências. É o momento de experienciar coisas novas, como drogas, sexo, namoro. E mais uma vez aparece o termo violência, que merece destaque, pois apareceu nas periferias de jovens e de juventude, o que pode indicar a associação juventude-violência tão falada na mídia e nos discursos do dia a dia. 
A representação de jovens e de juventude para os dois grupos apresenta elementos bem semelhantes. Para os jovens investigados, a juventude é compreendida como uma fase do desenvolvimento humano, fase de descobertas e aprendizado, no sentido de acúmulo de experiências; estudo ou educação, relacionados ao momento da escola e da faculdade; conciliação ou mesmo divisão entre o lazer, a balada, os passeios com os amigos e a liberdade que começa a ser adquirida e a responsabilidade de construção do futuro que começa a ser pensado a partir da escolha da profissão e do ingresso na Universidade.

Desenvolvimento, esperança, violência, grupos são elementos que aparecem nas periferias dos dois grupos. Aprendizado e responsabilidade têm frequências mais elevadas na tabela 4, mas aparecem com menores frequências na tabela 3, no núcleo periférico, já com os termos drogas e sexo acontece o oposto.

Os dois grupos (masculino e feminino) caracterizaram a juventude como um período de planejamento ou de preparação para o futuro, relacionando-a com o período da faculdade, que os participantes estão vivenciando no momento, o que mostra a ligação entre as representações de jovens (eu e as pessoas do meu grupo) e a juventude (categoria na qual me insiro, me identifico e me defino) como mostram as falas:

Quando eu penso em juventude o que me vêm à cabeça é assim que é essa parte da nossa vida, essa parte da faculdade, uma fase muito de contradição, de você não saber o que vai fazer da vida, você fica pensando o que você vai fazer no futuro, o que você vai ser quando terminar a faculdade. É essa fase única da vida meio perturbada, mas ao mesmo tempo é assim essa fase da vida que você costuma se divertir mais, faz tudo o que você quiser praticamente. Então quando me vêm juventude eu penso que é uma época da vida (M7).

Pra mim, a juventude, eu não vou colocar como uma fase nem como um período porque eu acho que não é isso, eu acho que a gente meio que cria muito essas coisas, mas eu colocaria como sendo assim uma das etapas em que a gente busca muito uma realização profissional, claro que dentro de cada limitação. Eu estou falando assim porque eu olho muito a mim e aos meus amigos, então é uma realização profissional, fazer uma faculdade, sair com os amigos. Outros têm planos de casar, né, pensando dos 18 até os 30, então alguns têm vontade de casar, ter filhos. Então eu acho assim que é uma etapa marcada principalmente pela vontade de fazer planos (F1).

Nas falas das jovens, a juventude foi caracterizada, principalmente, por ser um momento de fazer planos e executá-los, momento de pensar e planejar o futuro profissional ou familiar. Além disso, enquanto algumas falas apontavam na direção de considerar a juventude como uma construção social, outras a colocavam como uma fase passageira da vida, fase preparatória para a vida adulta.

Eu entendo como juventude uma coisa mais temporal, assim. É uma coisa que eu relaciono mais com a questão do tempo, não fico muito focada na questão da idade, sabe? Se eu estou na juventude ou não, não estou. Então seria uma coisa na qual cada um se define, eu acho, estar ou não nesse tempo (...) não só a pessoa [se define que está na juventude], porque a sociedade também define se você está ou não dentro desse grupo... (F2)

Olha, a juventude pra mim é a parte mais difícil da nossa vida. É uma fase, pra mim é uma fase porque passa. Mas eu acho que é uma fase de descobrimento. (...) Quando você é jovem, você descobre o seu eu no âmbito social, você começa a tentar descobrir: "meu Deus, o que é que eu vou fazer da vida? Porque a partir de agora eu não vivo mais com os meus pais". Mesmo se vive, mas já tem aquela expectativa de não morar e há uma preocupação social mesmo: onde é que eu vou morar? o que é que eu vou fazer? Que padrão que eu devo seguir? Você está entrando dentro dos padrões sociais, então eu acho que é a parte onde deveria ter mais auxílio, acredito, para o jovem se identificar, pois é muito difícil para o jovem concluir sozinho que cidadão ele será, entendeu? Ainda mais uma pessoa que não teve um bom estudo, não teve um bom conhecimento geral social, então eu acho que fica difícil na hora dele fazer as escolhas. (F 5). 
Enquanto para as meninas a juventude se caracteriza, principalmente, por ser uma fase de fazer planos para o futuro, para os jovens do sexo masculino, seria uma fase de diversão, de crescimento pessoal e aquisição de responsabilidades, caracterizada, portanto por um paralelo entre ganho de autonomia e dependência financeira dos genitores.

Vai até um pouco mais velho mesmo. Mas se você considerar as mudanças sociologicamente, uma pessoa com 15 anos hoje em dia já pode ser considerada jovem. (...) a primeira coisa que vêm à minha cabeça são esses grupos de igreja, juventude de tal igreja, mas assim, seriam aquelas pessoas que vão procurar o primeiro emprego, pessoas mais jovens, entre 18 e 30 anos mesmo, esse grupo de pessoas. Seria uma fase que você passa a ser mais economicamente ativo, analisando nesse aspecto econômico, assim. Vão ser as pessoas que vão ter um papel definidor no futuro do País, juventude me lembra muito disso, aquela coisa de que os jovens vão mudar o país. Os jovens seriam esse conjunto de pessoas, até os 30 anos pode ser mesmo. Até porque depois dos 30 você mudar já é bem mais difícil, não é. Então juventude é isso: 15 a 30 anos, 18 a 30 anos é só um número, mas no geral o jovem tem essa diferença. [...] Mas eu acho muito forte um adolescente de 17 anos, por exemplo, tomando uma decisão vai valer a vida dele toda, porque no mundo, na sociedade, não tem como desvencilhar isso, por que tipo hoje às vezes você toma uma decisão errada, mas aí você tem que seguir aquilo, porque você não tem tempo, e eu que não sou de uma família rica e tal. Então é isso ou aquilo, matar ou morrer, mais ou menos, é 8 ou 80. (M 2).

A fim de uma aproximação maior com o conhecimento sobre a juventude e os jovens, questionamos os jovens quanto à vivência da juventude na atualidade. Observamos que de maneira geral os participantes fizeram uma comparação entre a própria vivência e a vivência de outros. Os participantes do sexo masculino salientaram, sobretudo, as semelhanças e diferenças entre as próprias vivências e as vivências de outros jovens, enfatizando o momento que estão vivenciando, momento de tomar decisões, como "qual profissão seguir", ganho de autonomia, mas ao mesmo tempo a dependência dos pais.

Ao diferenciarem-se de outros jovens, bem como ao demarcarem diferenças entre o seu grupo de amigos e outros grupos de jovens, os participantes estão demarcando a importância dos grupos de pares como elementos característicos da juventude e característicos da RS de jovens e juventude.

A diversão, baladas, internet, bebidas e a liberdade de expressão foram tratadas como momentos comuns a todos os jovens, como algo que confere a eles um ponto de igualdade aos outros jovens e a sensação de aproveitamento do momento, como podemos ver a seguir:

Para mim está sendo muito difícil morar sozinho, porque eu sempre fui muito ligado à minha mãe e é um pico de autonomia que as pessoas às vezes têm que tomar muitas decisões na vida. Então, como é que eu vivo a minha juventude hoje: vivo com prudência e com responsabilidade, porque se eu estou aqui, por exemplo, fazendo esta entrevista aqui é porque a minha mãe me deu a oportunidade de estar aqui, usando o dinheiro dela, então eu vou tentar me diferenciar $e$ aproveitar o tempo que estou aqui. E eu tenho trejeitos da juventude atual, então eu saio, bebo, eu não uso drogas além de bebidas e eu tenho que estudar para me inserir no mercado de trabalho, sei lá, a minha vivência na juventude é essa, porque eu nunca fui muito de festas, sempre fui muito NERD, então eu não tenho o que falar, eu gosto muito de jogar, eu sempre fiquei em casa jogando, mas é isso (M2).

As participantes do sexo feminino também apresentaram em suas falas uma diferenciação entre a juventude vivenciada por elas e a vivenciada por "outros jovens", ressaltando os aspectos positivos das suas vivências e assinalando os "aspectos negativos" ao que é comum à juventude em geral. $O$ momento vivenciado na universidade, os planos para o futuro, a aquisição de liberdade antes negada pela família e as festas com os amigos foram elencados pelas participantes F1 e F2 como pontos positivos de vivenciar a juventude. 
Diferentemente, a participante F3 fala de assumir novas responsabilidades, pois já não mora mais na casa dos pais, logo, precisa ser mais responsável, porém ressalta que outros jovens não fazem a mesma coisa; em contraponto, as participantes F4 e F6 enfatizam que atualmente os jovens estão assumindo responsabilidades que deveriam ser assumidas na fase adulta cada vez mais cedo, o que tem colaborado para a não-vivência deste momento considerado importante.

As participantes F5 e F7 ressaltam a influência da religião na vivencia da juventude; F5 fala que as pessoas consideram que ela pulou a juventude, já que ela é evangélica, não gosta de sair para baladas, trabalha desde cedo e é casada; ressalta também a ideia da juventude como um momento natural de questionamento e de proposição de mudanças. A F6, que está noiva, aponta que tal qual todos os jovens, mora com os pais, mas que vai casar por escolha própria e ainda vai continuar "tendo essa liberdade" (F6) de estudar e correr atrás dos seus sonhos profissionais.

\begin{abstract}
Hoje os meus amigos, colegas, enfim, as pessoas da minha idade que me circundam têm atitudes diferentes, por exemplo: "ah, cansei de estudar a semana inteira, então quero ir para a balada, quero beber, quero extravasar porque eu quero me distrair". Eu não consigo fazer isso, é um meio no qual eu não me sinto bem, então se eu estou cansada eu vou ver um filme, eu vou relaxar em casa, posso tomar uma cerveja, com certeza, mas eu vou procurar me relaxar de verdade e eu acho que o relaxar deles é tentar fugir um pouco da realidade, é sair, dançar, beber, extravasar mesmo, então eu me considero um pouco diferente dos jovens de hoje em dia por isso, mas eu acho que tem uma influência familiar muito grande. Eu sou assim, eu sou cristã, eu tenho conceitos cristãos e isso influencia nos meus gostos, eu cresci a vida inteira ouvindo que não é bom você ir para a balada, hoje eu não vou porque eu não gosto, mas eu sei que o meu não gostar tem parte no que eu aprendi. Então, ser jovem hoje eu acho que é complicado, né? Então assim, não acredito que seja a juventude de hoje em dia, acho que seja a juventude em si, a gente tem um instinto de tentar mudar a coisa que não tá boa, ah, vamos à luta, gente, vamos fazer alguma coisa, vamos radicalizar, entendeu? 0 jovem tem isso, tem essa energia e eu acho que quando passa a juventude isso um pouco se perde, você tem compromissos extras, tem filhos, então você não pode se dedicar tanto à sociedade como quando você é jovem. Eu acredito que seja isso (F5).
\end{abstract}

Ao ressaltarem em suas falas o compromisso com a responsabilidade e com os estudos em escala superior à diversão, os participantes apontam a ideia de que estão "no caminho certo", ou seja, fazendo o que se espera que o "bom" jovem faça, como apontaram Martins, Trindade e Almeida (2003) e Paixão, Almeida e Lima (2012) ao falarem do adolescente normal, que seria aquele compromissado com a própria educação e com o futuro. A rebeldia, atrelada à transgressão, que também vigora nas falas dos participantes, ancoram a RS de jovem na ideia do "ser que precisa ser 'domado' para assumir as suas responsabilidades e, futuramente tornar-se um adulto" (Martins, Trindade \& Almeida, 2003, p. 565), aproximando-os dos adolescentes que eles tanto insistem em diferenciar-se.

As falas em torno da juventude estão sempre em comparação com a adolescência e/ou com a idade adulta. Com a adolescência, a comparação é no sentido de demarcar diferenças em termos de maturidade e experiências; já as comparações com a idade adulta colocam o adulto como uma meta, o jovem estaria se preparando para "virar" adulto, construindo a sua personalidade e tentando descobrir o seu lugar no mundo adulto. Observamos então, que ao falar dos jovens, os participantes falam de si e do seu grupo, buscando em grande medida uma identificação com os elementos que positivem a si mesmo e ao grupo e preserve a sua identidade positiva.

As entrevistas vêm para ratificar o que foi observado nas evocações. Os jovens são representados como pessoas que ora estão em uma faixa superior à da adolescência ora são 
compreendidos como adolescentes pela ausência de responsabilidades e experiências que os coloquem em pé de igualdade com os adultos. A noção do jovem como um ser em construção, ou em preparação para a vida adulta está clara nos resultados dos dois instrumentos, o que pode reafirmar a centralidade dos elementos Estudo, Faculdade $e$ Futuro. O núcleo periférico permite contradições, por isso não é de se estranhar que associado à rebeldia, o jovem apareça como possível transgressor de normas e regras, mesmo que a transgressão não seja o que se espera socialmente dos mesmos. Estariam estes jovens representando o que Menandro (2004) categoriza como a juventude que não deu certo. A juventude, para os participantes da pesquisa, seria representada como um período de aquisições de conhecimento e responsabilidades, mas ao mesmo tempo marcada como um período de vivências de curtição e alegria.

\section{Considerações finais}

Objetivou-se neste estudo compreender as representações sociais sobre jovem e juventude de jovens universitários. Ao final do estudo compreende-se que as representações sociais de jovem e de juventude se entrelaçam, de modo que a representação de juventude como uma fase da vida, momento de preparação para a vida adulta, marcada pela aquisição de responsabilidades através do estudo $e$ do ingresso na faculdade, colabora para uma representação do jovem como alguém que ao mesmo tempo precisa dedicar-se ao futuro - assumir responsabilidades, mas sem deixar de aproveitar o momento vivenciado, no qual ainda é aceitável socialmente a transgressão de algumas regras, demarcando a rebeldia e a irresponsabilidade como traços marcantes no imaginário social sobre a juventude.

A diversão sinaliza um aspecto relevante da juventude, algo que se assemelha a uma obrigação dos jovens, que devem estudar e dedicar-se ao futuro, mas sem deixar de se divertir, de aproveitar o momento. A rebeldia, a transgressão e a violência também aparecem como características da juventude, corroborando com a imagem estereotipada do jovem como um problema social.

Ao final do trabalho podemos traçar alguns possíveis elementos centrais e periféricos que podem compor a representação social de jovem e de juventude, porém enfatizamos a importância de um estudo de confirmação da centralidade. Podemos ainda observar que a juventude é enfocada como uma fase da vida que visa atingir objetivos propostos pelos adultos. Os jovens não questionaram em nenhum momento a possibilidade de não ingressar em uma faculdade ou de fazer um curso técnico, por exemplo, como outra opção viável para a juventude, as falas giraram em torno do que eles conhecem como sendo o ideal de juventude.

Podemos dizer que os jovens compreendem o jovem como alguém que vivencia uma fase - a juventude- cuja expectativa social é que seja um momento de especialização e preparação para a vida adulta e que, em grande parte, os jovens agem segundo tal expectativa. Mas uma fase que também é balizada pelo ganho de liberdade e pela curtição, diversão e passível da prática de atos ilícitos, como o uso de drogas. A rebeldia, a imaturidade e a transgressão também estão presentes nestas representações, mostrando que os jovens não se aproximam somente dos adultos, mas também conservam características que tradicionalmente marcam a adolescência, mas também conservam características que, segundo Paixão (2012), tradicionalmente marcam a adolescência, como a rebeldia. Assim, percebemos que os jovens ao buscarem uma definição da juventude a 
colocam ali entre a adolescência e a idade adulta, em uma tentativa de se distinguir da adolescência e se aproximar da adultez, mas sem perder características que eles consideram próprias da juventude, como o momento de buscar o seu lugar no mundo sem o peso das responsabilidades de um adulto, como ressaltou o participante $\mathrm{M} 1$. $\mathrm{O}$ jovem é então um ser em processo de crescimento pessoal e social, que deve assumir um compromisso com o futuro, porém um ser ainda imaturo que pode envolver-se em atos ilícitos.

Foi possível notar ainda a relação constante entre sujeito e objeto no estudo das RS, de modo que ao falar sobre o jovem e a juventude, os participantes falavam de si, da sua visão de mundo e das suas ações cotidianas. Os discursos aqui encontrados sobre o jovem e a juventude ancoram-se nas teorias que encontramos na literatura, nas falas dos jornalistas que noticiam a violência cotidiana e na própria legislação. Apesar do enfoque nos elementos positivos, a aproximação entre juventude e transgressão ainda é marcante, ressaltando a influência do que é dito socialmente sobre a juventude na construção da percepção de si e do seu grupo.

Julgamos relevante um estudo que foque a relação entre representação social e identidade, pois não objetivamos discutir esta relação no presente trabalho. Por fim, do ponto de vista metodológico, não foram encontradas diferenças significativas na maioria dos elementos que foram elencados pelos participantes do sexo feminino e do sexo masculino. Além disso, a maior parte dos elementos que foram classificados como supostos componentes do núcleo central da representação de jovem e de juventude pareceram nas entrevistas.

\section{Referências}

Abramo, H. W. (1997). Considerações sobre a tematização social da juventude no Brasil. Revista Brasileira de Educação - ANPED, 5(7), 25-36.

Aguiar, W. M. J., Bock, A. M. B. \& Ozella, S. A orientação profissional com adolescentes: um exemplo de prática na abordagem sócio-histórica. In: Bock, A. M. B., Gonçalves, M. G. M. \& Furtado, O. (Orgs.). Psicologia sócio-histórica: uma perspectiva crítica em psicologia. São Paulo, Cortez, 2001, pp. 163-178.

Abric, J. C.(1998). A abordagem estrutural das representações sociais. In: A.S.P. Moreira \& D. C. Oliveira (orgs). (1998) Estudos interdisciplinares de representação social (pp.27-38). 2a ed. Goiânia: ABDR.

Almeida, A. M. O. (2005). A pesquisa em representações sociais: Proposições teórico-metodológicas. In Santos, M. F. \& Almeida, L. M. Diálogos com a teoria das representações sociais (pp.119-160). Alagoas: UFAL/ UFPE.

Arruda, Ângela (2005). Despertando do pesadelo: a interpretação. In: Moreira, A. S. P., Camargo, B. V., Jesuíno, J. C. \& Nóbrega, S. M. (Org.). (2005) Perspectivas teórico-metodológicas em representações sociais. Editora Universitária, UFPB, Paraíba.

Bardin, L. (2007). Análise de conteúdo. Lisboa: Edições 70.

Bock, A. M. B., Furtado, O., Teixeira, M. L. T. (2008). Psicologias. Uma introdução ao estudo da psicologia, 14 ed. São Paulo: Saraiva.

Brasil (2013). Lei no 12.852, de 5 de agosto de 2013. Institui o Estatuto da Juventude e dispõe sobre os direitos dos jovens e dá outras providências. Brasil, Distrito Federal: Casa Civil.

Cardoso, R. C. L., Sampaio, H. M. S. (1995). Bibliografia sobre a juventude. São Paulo: Edusp.

Cassab, Clarisse (2011). Contribuição à construção das categorias jovem e juventude: uma introdução. Locus: revista de história, Juiz de Fora,17, 02 p. 145-159. 
Chaves, A. M. \& Silva, P. L. (2011). Representações sociais. In. L. Camino, A. R. R. Torres, M. E. O. Lima e M. E. Pereira. Psicologia Social: temas e teorias. Brasília: TechnoPolitik, 299-349.

Espíndula, D. H. P., Alves, L. S., Carvalho, L. A., Almeida, M. B., Cruz, S. T. M. (2015). Representações Sociais de Crack e Adolescência na Imprensa Pernambucana. Temas em Psicologia - 2015, Vol. 23, no 2, 281-292

Goes-Piazzarollo, D. C. G. Fatores de risco e de proteção presentes na vida de adolescentes cumprindo liberdade assistida: permanência e evasão escolar (Dissertação de mestrado). Programa de PósGraduação em Psicologia, Universidade Federal do Espírito Santo, Vitória, ES, Brasil.

Groppo, L. A. (2000). Juventude: Ensaios sobre sociologia e história das juventudes modernas. Rio de Janeiro: Difel.

Groppo, L. A. (2006) A condição juvenil e as revoltas dos subúrbios na França. Política \& Sociedade, 8, 89-121.

Martins, P. O, Trindade, Z. S. \& Almeida, A. M. O. (2003) O ter e o ser: representações sociais da adolescência entre adolescentes de inserção urbana e rural. Psicologia: Reflexão e Crítica.

Martins, J. C. de O., Lefevre, F., Lefevre, A. M. C., \&Oliveira, G. R. T. (2012). O tempo livre com qualidade a partir de discursos coletivos. Revista Mal-estar e Subjetividade, 12(1-2), 41-72.

Menandro, M. C. S., Trindade, Z. A., Almeida, A. M. O. (2010). Representações sociais da adolescência/juventude a partir de textos jornalísticos. Vitória: GM Gráfica e Editora.

Menandro, M. C. S. (2004). Gente Jovem Reunida: Um estudo de representações sociais da adolescência/juventude a partir de textos jornalísticos (1968/1974 e 1996/2002). Tese (Doutorado em Psicologia). Doutorado em Psicologia, Universidade Federal do Espírito Santo.

Oliveira, M. B., \& Rosa, E. M. (2010) Juventude, violência e alteridade. Temas em Psicologia 18(1), $113-121$.

Ozella, Sérgio (org.). (2003). Adolescências Construídas: a visão da psicologia sócio-histórica. São Paulo: Cortez, 2003.

Pais, J. M. (1990) A construção sociológica da juventude-alguns contributos. Análise Social, 25(1), 139-165.

Paixão, D. L. L., Almeida, A. M. O., Lima, F. R. (2012). Representações sociais da adolescência por adolescentes e jovens. Psicologia e Saber Social, 1(2), 278-294.

Pappámikail, L. (2004) Relações intergeracionais, apoio familiar e transições juvenis para a vida adulta em Portugal. Sociologia, Problemas e Práticas, 46, 91-116. Recuperado de: http://www.scielo.oces.mctes.pt/pdf/spp/n46/n46a05

Pappámikail, L. (2010) Juventude(s), autonomia e sociologia: questionando conceitos a partir do debate acerca das transições para a vida adulta. Revista do Departamento de Sociologia da FLUP, 20, 395-410.

Peralva, A. T. (2007). O jovem como modelo cultural. In. “Juventude e Contemporaneidade”. - Brasília: UNESCO, MEC, ANPEd.

Polli, G. M., Wachelke, J. (2013). Confirmação de Centralidade das Representações Sociais pela Análise Gráfica do Questionário de Caracterização. Temas em Psicologia - 2013, Vol. 21, no 1, 97 - 104

Valadão, C. C. (2013). A gente não quer só comida: Políticas públicas para a juventude no Espírito Santo. Dissertação de Mestrado.

Vavassori, M. B.; Toneli, M. J. F. (2015). Propostas de Redução da Maioridade Penal: a Juventude Brasileira no Fio da Navalha? Psicologia: Ciência e Profissão, 35(4), 1188-1205

Vergès, P. (1992). L'evocation de l'argent: une méthode pour la defi nition du noyau central de la représentation. Bulletin de Psych ologie, 45(405), 203-209

WHO, World Health Organization. (1986). Young People's Health - a Challenge for Society. Report of a WHO Study Group on Young People and Health for All. Technical Report Series 731. Geneva. 